\title{
New Data about the Structure of the Earth's Crust according to Regional Geophysical Investigations' Results within Yakutian Kimberlitic Subprovince
}

Mitioukhine, S.I., Manakov, A.V., Poltaratskaya, O.L., and Romanov, N.N.

YaGEER\&D CNIGRI, ALROSA Co. Ltd. Chernyshevsky Sh. 7, Mirny, 678170, Sakha (Yakutia), Russia.

Introduction

Investigations with the aim of perfecting the methods of kimberlites and associated rocks' forecasting keep on being relevant. One of perspective directions is investigation of the structure of geophysical fields: magnetic one, the field of gravitational force, electromagnetic and seismic fields. It is taken into account therewith that solutions of reverse tasks of geophysics from mathematical point of view are related to the category of "noncorrect" ones. In practice it is expressed in multiversion of resulting constructions: several geological models can simultaneously satisfy the field under observation. Complex analysis of geophysical data is one of the ways to increase reliability of constructions. In this case the aim is to construct the model of a geological section, different parameters of which do not contradict each other. Below there are the results of an experiment with application of geophysical material concerning Yakutian kimberlitic subprovince.

Methods of geophysical data processing

The territory of Yakutian kimberlitic subprovince is located within the limits of eastern part of the Siberian Platform and is related to the category of the most investigated one by regional and small-scale geophysical methods. They include areal survey by method of magnetotelluric sounding, areal and profile exploration by deep seismic method, magnetic and gravitational surveys of $1: 200000$ scale. The methods of interpretation of magnetotelluric sounding were based on construction of pseudogeoelectrical sections with the help of controlled transformation of Molochnov - Le Viyet. This procedure was carried out after preliminary dynamic correction of initial data MTS (1) on the basis of three-dimensional film modelling. Such an approach allowed to minimize distortions determined by surface heterogeneity and assess specific features of distribution of resistance in the Earth's crust. Processing and interpretation of magnetic and gravitational field values was based on investigation of spectrum signal. The aim was to determine petrophysical and spatial parameters of the targets, to which the effect in this or that part of the spectrum corresponded. It was revealed that the structure of gravitational and magnetic fields was characterized by common regional trend. In the transformed magnetic field it is expressed in the change of values from 50 to $120 \mathrm{nT}$ in northern direction and in gravitational field in increasing of values with gradient 0.06 $\mathrm{mGl} / \mathrm{km}$. Data analysis of deep seismic exploration has indicated that the trend of Moho surface is described in similar way with the growth of thick layers of the Earth's crust at gradient of $1.5 \backslash 100 \mathrm{~km}$. By combining these parameters calculation of gravitating effect 
created by the Earth's crust has been gained. Further on the same computational operation was carried out for individual layers of the crust separated by Conrad discontinuity. The position of this discontinuity was also determined according to the data of seismic exploration. Subsequent reduction of potentional fields allowed to exclude the influence of sedimentary cover's section, thick layers of which vary from 1.1 to $7.0 \mathrm{~km}$ (according to the data of drilling and seismic exploration). In the result of the performed computational operations complex geophysical model of consolidated Earth's crust within Yakutian kimberlitic subprovince has been drawn up and regionalization of the territory according to specific features of distribution of mineral masses in the section of the crust has been started.

\section{Results of the territory's regionalization}

Classification of geophysical heterogeneities in the section of the Earth's crust made it possible to reveal two main types of geostructural areas within the borders of the noted territory: block and linear-zonal ones. Tyungsky, Aykhal'sky and Botuobinsky blocks are refered to the first type. In magnetic and gravitational fields the blocks are responded by anomalies of decreased values with specific low-gradient close to isometric in shape anomalies of the second order. Average specific density of rocks in blocks is assessed in 2.8-3.0 $\mathrm{g} / \mathrm{cm}^{3}$, and velocity of seismic waves' propagation in $6.6-6.77 \mathrm{~km} / \mathrm{sec}$. Close to single-criterion character of electromagnetic field's distribution, high resistance of the crust in its upper part with availability of contrast conducting layer, as well as lateral stability of the types of geoelectrical section within each block are earmarked for geostructural areas of block type. Geostructural areas of linear-zonal type have principally different geophysical image. They are distinguished by extended linear anomalies of diverse symbol in gravitational and magnetic fields. Velosity of springy oscillations' propagation within the zones constitutes 6.5-6.55 km/sec. Electromagnetic field within their limits carries quasi-two-criterion character with gradient distribution of resistance along lateral and polarizes in accordance with the direction of linear structures. Making use of the data about composition of crystalline basement (xenoliths of crustal rocks in kimberlites, core of deep boreholes) one can make the following conclusions about the structure of the region's crust. Evidently, geostructural areas of block type represent the nucleus of granulite filling, which are composed mostly by metabasalts. They are the most ancient formations in age, the forming of which completed in the period of 1.902.0 milliard years. Geostructural areas of linear-zonal type respond to the zones of collisions, which were formed in the result of tectonic interaction of the described above blocks in the period of 1.7-1.8 milliard years. They are gigantic overthrusts with developed migmatization and diaphthoresis in the section. Magmatic complexes are represented by anorthosites and intrusive granites. The rocks have suffered regressive metamorphosis before amphibolite facies.

So far within the explored area 5 kimberlite fields have been allocated, each of which contains pipes with industrial level of diamondiferousness. It is noticeable that all kimberlite fields are drawn towards the borders of geostructural areas of the block type in the place of their joint with the zones of contiguous deep-seated faults, but no kimberlites 
have been found within the areas of linear-zonal type. It is possible that there is interrelation between distribution of mineral masses in the section of consolidated crust and material characteristics of upper mantle substrate.

\section{References}

Feinburg, A.B., Geren, R., Andie, P., and Poltaratskaya, O.L., 1995, Dynamic correction of amplitude curves of magnetotelluric sounding distorted by the influence of close to the surface heterogeneities: Physics of Earth, ${ }^{17}$, p. 29-34. 